\title{
Common European Framework of Reference (CEFR): A Review on Teachers' Perception \& Plurilingualism
}

\author{
Nadrah Zainal Abidin, Harwati Hashim* \\ Faculty of Education, Universiti Kebangsaan Malaysia, Selangor, Malaysia \\ Email: ^harwati@ukm.edu.my
}

How to cite this paper: Abidin, N. Z., \& Hashim, H. (2021). Common European Framework of Reference (CEFR): A Review on Teachers' Perception \& Plurilingualism. Creative Education, 12, 727-736.

https://doi.org/10.4236/ce.2021.124051

Received: February 19, 2021

Accepted: April 5, 2021

Published: April 8, 2021

Copyright $\odot 2021$ by author(s) and Scientific Research Publishing Inc. This work is licensed under the Creative Commons Attribution International License (CC BY 4.0).

http://creativecommons.org/licenses/by/4.0/

\begin{abstract}
Common Framework of Reference (CEFR) is a document produced by the council of Europe ( $\mathrm{CoE}$ ) to set a standard for teaching and learning English as the Second Language (ESL). Propelled by the need to situate Malaysia English language parallel to the standard of the European countries, the Ministry of Education Malaysia rushed the adaptation of CEFR framework into Malaysia education system. Teachers' lack of training and understanding on CEFR as well as unsuitable content used in the textbook are among the main challenges faced by teachers to name a few. Nonetheless, the key concept of Plurilingualism which served as the principle in CEFR has been given very minimal focus in the syllabus. Considering Malaysia as a multilingual and multicultural country, there is a potential of English Second Language learners to benefit from the concept of plurilingualism given appropriate training and exposure given to the teachers as the gatekeeper of knowledge and information. In fact, plurilingualism could also be the missing piece that could help aid teachers' understanding of the framework better.
\end{abstract}

\section{Keywords}

Common European Framework of Reference (CEFR), English as Second Language (ESL), ESL Learners, Plurilingualism

\section{Introduction}

Due to globalization and competitiveness in the job market, there is a need for individuals to be able to communicate fluently in English as it is the lingua franca (Yamat et al., 2014). Hence, producing students who are proficient in English according to the international standard has become the key agenda for many 
East Asia areas namely Singapore, China, Japan as well as Taiwan to name a few (Darmi et al., 2017; Read, 2019). Since the introduction of Common European Framework of Reference (CEFR) in 2015, major changes have been made in the English Education Policy. Beginning from primary to tertiary level, all assessments are aligned to the CEFR format. The objective is to standardize English level in Malaysia based on the European format and standard (Mohamad Uri \& Adb Aziz, 2018). Since then, CEFR has gained immense popularity from policymakers not just in Malaysia, but worldwide as CEFR acts as the international benchmark of users' language proficiency (Read, 2019). However, there are several issues pertaining the implementation of CEFR as it is adapted from the European context (Mohamad Uri \& Adb Aziz, 2018). Surprisingly, there are limited research studies in Malaysia pin pointing out the absence of plurilingualism as the underlying key concept of the CEFR framework. This study will shed some light on the introduction of CEFR in Malaysia, other researches related to the implementation of CEFR as well as some evidence on the potential of embedding the concept of plurilingualism in Malaysia's CEFR.

\section{CEFR in Malaysia \& Other Researches Related to the Implementation of CEFR}

The need to increase marketability of Malaysia's graduates to becoming a fluent speaker marked the path of CEFR in the Malaysia Educational system. In 2013, a Cambridge Baseline Study was conducted to obtain the information on Malaysian students and English teachers' language proficiencies from primary to tertiary level. The findings which were documented in the Roadmap (document that set the key agenda of English Language Education at all levels based on the standard set by CEFR) revealed that the current English Education system is unable to produce human resources who are fluent and marketable for the international job prospect (Don et al., 2015).

Raising Malaysia' standard of English language proficiency against the CEFR allows Malaysia's English to be accepted and acknowledged according to the international standard (Don et al., 2015). However, several issues have been raised by teachers in terms of teachers' knowledge, preparedness, time constraint, the use of imported textbooks as well as minimum exposure due to lack of training (Mohamad Uri \& Adb Aziz, 2018).

Despite of the continued effort to utilize the framework in Malaysia context, there are very few studies that focused on the aspect of plurilingualism and plurilculturism. Considering plurilingualism and plurilculturism as the two main aspects focused in CEFR framework, the increasing need for more studies to be conducted to identify the potential and benefits of the framework from these aspects cannot simply be undermined nor neglected.

In a study on the assessments' instrument and frequency of using the tools in regards to CEFR align context, findings showed that for the past two years, many teachers had problems aligning the assessments based on the CEFR descriptors. 
The study also revealed that teachers resorted to using group discussion, i-Think maps, mind mapping and oral quizzes for various assessment activities. It also revealed that majority of teachers relied heavily on the textbook exercises and viewed it as the main source of reference when assessing the students (Azli \& Akmar, 2019).

Findings from a study on teachers' views on students' performance in English Language proficiency courses Via CEFR descriptors reflected a misalignment of teachers' view and students' English language proficiencies courses specifically in reading and writing components. Few teachers believed that many of their students struggled to extract main ideas from a rich text. A similar view was also recorded on the writing component as many teachers believed their students were unable to pen clear, rich and organized texts (Darmi et al., 2017).

Looking at the appropriateness and applicability of English Assessment Against CEFR Global Scale based on teachers' judgement, findings revealed that teachers' understanding of CEFR global scale is sufficient as majority of them were able to successfully rank the assessments according to the CEFR standard correctly. Talk, descriptive and argumentative writing were recommended by the teachers to be included in the CEFR for SPM English syllabus as well as all the writing assessments. Generally, teachers were able to relate to CEFR and found the global scale can be used appropriately (Uri \& Aziz, 2020).

Based on a study on teachers' perception on the implementation of CEFR in Vietnam, findings revealed that the textbook used by the university, specifically for the non-native speaker at Hue University was not aligned with the CEFR learning outcomes. The textbook was negatively viewed and deemed irrelevant for the non-native English user's use. Another issue highlighted by the researcher was lack of time allocated to learn English based on the content from the book. This had caused teaching and learning to become very challenging for both teachers and students at the university (Nhung, 2019).

Mohamad Uri and Adb Aziz (2018) conducted a study on the teachers' awareness and the challenges on the implementation of CEFR in Malaysia found that teachers believed they needed more knowledge to implement CEFR in the classroom. Although the majority of teachers seemed to know the 6 levels of CEFR and the target level of CEFR for form 5 students upon completion, CEFR workshop was perceived as less helpful in terms of knowledge and familiarization of the framework. Findings further revealed that many teachers somehow read and were exposed to the document related to CEFR mostly from the workshop conducted by the Ministry of Education. Results also showed that most teachers agreed that CEFR is needed in response to globalization as it will help build the country's economy by producing fluent manpower.

From the aspect of teachers' belief and knowledge on the implementation of CEFR in Malaysia, findings showed that teachers interpreted the framework into their teaching differently. Some teachers believed that CEFR focused more on communicative aspect, hence, shifting the focus from writing and reading to de- 
vising more communicative activities. On the other hand, some teachers also believed that CEFR focused on speaking, reading, writing and listening, but emphasis was given on what students can produce from the situation given. Regardless, the majority of teachers agreed that the communicative aspect was centralized in their classroom activities to encourage students to speak up more. In term of assessment method, findings showed that most of the teachers did not understand how CEFR should be aligned with the curriculum as the knowledge they obtained from a 3 days program with the master trainers was somehow diluted, inadequate and may leave room for misinterpretation from the master trainer to the teachers (top down approach). On top of that, teachers were also burdened with other works which led them to rely heavily on the textbook although the context was less suitable to be used as examples in aiding students' understanding. Nonetheless, some teachers realized the need to find more information to aid their understanding on the implementation of CEFR. On the other hand, developing new materials for teaching and assessments was found to be very time consuming, hence many teachers resorted to using the textbook as it is guaranteed to be CEFR aligned. Many teachers simply followed the instruction by the Ministry of Education without having a proper understanding on how CEFR should be utilized in the classroom, thus could become a hindrance for both parties in achieving the learning objectives (Alih et al., 2020). The fact that many teachers didn't know the aims and objectives of CEFR validates the need for intensive training on CEFR implementation.

In Spain, it is revealed that teachers' understanding on the implementation of CEFR was on the façade (Díez-Bedmar \& Byram, 2019). Majority of the teachers were able to relate to CEFR in terms of the levels, competences and assessments as what they have experienced as a student and from the CEFR training. However, many important aspects which can revolutionize teaching and learning were overlooked such as plurilingualism, transparency, curriculum design as well as learners' profile. This happened as many teachers focused on aligning the assessment based on CEFR more with minimal attention on plurilingualism and plural culturalism. Another notable aspect worth to note is teachers' perception on the importance of CEFR in the classroom. Majority of the teachers ranked the importance of implementing CEFR in order of syllabus, method, textbook and exam in the secondary school. Very few teachers mentioned plurilingualism in their response (Díez-Bedmar \& Byram, 2019). This further supports the fact that teachers' knowledge and understanding of CEFR implementation is superficial.

In Vietnam, English Language teachers' perception in the implementation of CEFR revealed that teachers believed to fairly have the knowledge of CEFR framework, but displayed uncertainty in the way it was being implemented. However, teachers appraised the CEFR division of language proficiency for matching the level and descriptors in a way that makes learning outcomes more organized and concise. On top of that, CEFR can-do statements were utilized in devising class activities in which learners were made aware of the target to be 
achieved based on each level of CEFR descriptors. The clarity in the objective of each descriptor was deemed to be helpful and offers better direction in teaching (Ngo, 2017). It is interesting to note that teachers in Vietnam perceived the necessity and urgency to implement CEFR regardless of the readiness positively.

Based on the application CEFR on 9th grade EFL program in Turkey, findings showed that the concepts of plurilingualism and interculturalism were absent in the CEFR implementation although principles of communicative language competence, intercultural awareness, task-based learning, action-oriented approach, autonomous learning and self-assessments were evident. The findings further revealed that $9^{\text {th }}$ grade learners were not enthused with the course materials design. EFL programs were loosely administered by teachers as not all students can be involved in the class activities due to limited course hours. Findings from the study also showed that learners in class self-assessment were perceived problematic as the task demanded a higher level of proficiency. On the other hand, EFL' language teachers' seminars and I-service training were deemed less helpful in improving teachers' professional development. The descriptors used in CEFR were perceived as ambiguous when referring to the phrases used such as "spontaneously, fluently". Notably, based on data obtained from both closed-ended questionnaires and interviews, CEFR seemed to be more useful for professional communication compared to pedagogical practice. The researcher however mentioned that the data seemed to contradict with data collected from the open-ended questionnaires. Another concerning aspect raised by the respondents from their study were theoretical content and applicability in which is believed to have excessively influence on non-European language classes offered at the university (Yüce \& Mirici, 2019).

On the other hand, findings on English Teachers' Concern on Common European Framework of Reference for Languages (CEFR) based on the application of CBAM in 20 secondary schools in Negeri Sembilan Malaysia indicated that teachers were more receptive to the changes and displayed willingness to understand CEFR. Teachers' willingness to learn and adapt the framework was believed to be the result of their commitment in finishing the syllabus. Teachers also displayed openness to adapt to CEFR and understand the needs to embrace changes and rectify the problems that took place. However, the idea of working together to mitigate the CEFR related problems was seen less favorable among teachers (Lo, 2018).

According to Zhao et al. (2017) in their study on calibrating the CEFR against the China Standards of English for College English vocabulary education in China, findings showed that teachers experienced difficulties to rank CEFR B1, $\mathrm{B} 1+$ and $\mathrm{B} 2$ levels. However, teachers were able to rank $\mathrm{C} 1$ level without much problems. The researchers also raised the issue of teachers' judgement on CEFR descriptors to be ambiguous, hence an external validation is needed to increase the validity of their judgement. The findings can be extrapolated in Malaysia CEFR context as many teachers are not very well verse with CEFR framework. 


\section{Potential Benefits of Embedding Plurilingualism in Malaysia CEFR}

In Malaysia, the plurilingualism and pluriculturalism aspects were missing in the CEFR (Savski, 2019). Having Communicative Language Teaching foregrounding the implementation of CEFR and basing action-oriented approach as reference, teachers were trained to align their teaching according to the CEFR scale. However, the Action-Based Approach adopted by CEFR focuses less on "communicative" but more on "post communicative" way of teaching the language (Piccardo, 2010).

The implementation of CEFR in Malaysia doesn't seem to uphold the element of plurilingualism. Policymakers place their attention mostly on the CEFR band and adaptation of international exam and textbook which centralize on monolingual learning aiming to achieve native speaker proficiency level (Shahomy, 2011). In light plurilingualism, communicative competence is viewed as integrating and expanding the knowledge via assimilation of various communication resources (Piccardo, 2013). On the other hand, aspects that characterize communicative competence are dynamicity and unevenness. Basically, communicative competence changes according to the language and culture it comes in contact with. As a result, learners have their own take on language learning and set priority over certain aspects of communicative competence (Council of Europe, 2001).

Generally, there are two key concepts underlying CEFR framework which are plurilingualism and pluriculturalism. The two key concepts were initially meant to mitigate European political, integration and cultural issues in 1990 (Council of Europe, 2001). "Plurilingual individuals are the ones who are efficient users of several languages interchangeably. They do not preserve their knowledge of languages in different and separate repertoire; instead, they keep their knowledge of languages in an interrelated repertoire" (Yüce \& Mirici, 2019: p. 96). Meanwhile, pluricultural is defined as the individual ability to communicate in different cultures as the result of their interaction with the culture beforehand (Council of Europe, 2001). In comparison, Malaysia as a country with multiple races and ethnicity could fit in the context of plurilingualism and pluriculturalism perfectly to improve language learning.

Among the potential benefits of CEFR are promoting self-development and raising awareness from language, culture and political perspectives (Piccardo et al., 2019). Benefit of plurilingualism is further illustrated in CEFR as a concept which 1) learners are capable of developing learners' sociolinguistics and pragmatics competences 2 ) able to perceive the complexity of the language positively and 3) offers learners the liberty to strategize their learning in regards to the new context (Council of Europe, 2001).

According to Piccardo (2013), metalinguistic and metacognitive are key players in building and amplifying learners' proficiency through self-driven attitude. Both key players are the result from the combination of plurilingual and pluricultural elements and skills. Hence, it is imperative for teachers to understand 
that English Language learners have different ways of thinking as they come from different backgrounds with various kinds of life experiences that shape their motivation and anxiety towards language learning (Hufeisen \& Neuner, 2004). The cross-cultural and crosslinguistic encompassed by language learners could assist teachers to exploit and explore learners' metalinguistics and metacognitive skills in learning the language as well as to boast learners' confidence and self-efficacy (Piccardo, 2013).

Globally, individuals who embrace pluricultural and experience intercultural education in context could offer more to the betterment of humanity. Correspondingly, mutual understanding and respecting linguistic diversity would be useful in devising a more inclusive second language program (Balc \& Osman, 2019).

To sum up, plurilingualism and pluriculturalism stand as entities that coexisted together and language acts as a bridge that connects pluricultural competence and plurilingual competence with other elements of language learning (Council of Europe, 2001). Therefore, CEFR is an aspect which needs to be taken into consideration in language planning policy.

\section{Conclusion \& Implication}

Globalization is inevitable. In order to ensure the standard of English in Malaysia to be recognized, embracing CEFR is a necessity. Hence, it is not a surprise that many countries have also joined the CEFR bandwagon by adapting and modifying the framework accordingly. In fact, the urgency to leverage the Malaysia standard of English to the international standard is reflected in many research findings. As the implementation is still at infancy state, there are several loopholes that can be observed in the implementation of CEFR in Malaysia. One that is pointed out the most is teachers' limited knowledge on the CEFR framework itself. Without a clear construct of CEFR, the outcomes produced could produce much of a less desirable result.

Plurilingualism is another aspect of the CEFR spectrum that has been given less attention in the implementation process in Malaysia. As most researches focused on the descriptors, levels and assessments, it's imperative to incorporate plurilingualism as well as plural culturalism to maximize the impact of the framework on the outcomes produced in Malaysia education context. Instead, the idea of plurilingualism is silenced and substituted with the word "international" as a means to cover the broad horizon of CEFR (Savski, 2020).

Another aspect of CEFR that calls for further discussion is CEFR format in Malaysia which defies the concept of plurilingualism and plurilculturism as the layout foundation of teaching and learning the language. English teachers were expected to use all English when delivering the lesson, hence, the need to apply the concept of plurilingualism becomes less important. Similarly, the need to become plurilingual is also not reflected in the syllabus content as well as the textbook used at tertiary level. When the two crucial elements in the CEFR framework are undermined, the effectiveness of the framework could be se- 
riously compromised and eventually becomes less effective. Therefore, it could be said that one of the missing pieces that hinder teachers' understanding on the implementation of CEFR could be more than just the lack of training or understanding of the descriptors but also the understanding on the use of plurilingualism.

The incompatibility of textbooks used in the classroom has also been the major findings in many researches. Unlike primary and secondary, tertiary level of education does not have any specific textbooks for reference. For instance, in Malaysia, each polytechnic would produce their own version of a textbook for students' reference. Although lecturers have more freedom in terms of content writing, the adherence to the CEFR format is highly questionable. In regards to plurilingualism, providing learners with context might potentially produce a better result.

Implications on embedding plurilingualism and plurilculturism can be expected at higher learning institution syllabus content and learning direction. Learners who feel inferior and intimidated by the language would be able to feel more at ease in learning the second language when the content is more familiar and relatable to them (Galante, 2020) After all, among the main objectives of CEFR is to support plurilingualism and diversification of learners by focusing on the quality and transparency based on learners' need, interest and age (CoE, 2018).

Another implication would be on learners' social skills. Learners who are able to interact and convey their intended messages clearly would be able to contribute more in terms of ideas and perspectives. Plurilingualism offers a fair chance for speakers to exploit their potential in study as well as at the workplace. When language is no longer the major hindrance, learners would be able to speak up with less anxiety and groping for words (Ross, Dooly, \& Hartsmar, 2012)

As a conclusion, the importance of CEFR has been acknowledged and understood by most teachers. The issues that were constantly raised is lack of understanding and training for them to implement in their teaching. Therefore, providing in depth training is critical to ensure the students' success in achieving the target level. In addition, plurilingualism should seriously be taken into consideration as Malaysia is after all a multiracial and multilingual country, hence let's embrace the uniqueness of our diversity into the classroom for the betterment of Malaysian English level of proficiencies.

\section{Acknowledgements}

The authors would like to thank Universiti Kebangsaan Malaysia under the Research Grant number 1) GG-2020-027 and 2) GG-2019-077 for supporting this project.

\section{Conflicts of Interest}

The authors declare no conflicts of interest regarding the publication of this paper. 


\section{References}

Alih, N. A. C., Yusoff, M. A. M., \& Abdul, A. H. (2020). Teachers' Knowledge and Belief on the CEFR Implementation in Malaysian ESL Classroom. Educational Research (IJMCER), 2, 126-134.

Azli, N., \& Akmar, A. (2019). Implementation of CEFR-Aligned Assessment Tools in Malaysian ESL Classroom. Asia Proceedings of Social Sciences, 4, 7-10. https://doi.org/10.31580/apss.v4i2.688

Balc, T., \& Osman, A. (2019). Schriften Zur Sprache Und Literatir Ele: Vol. III (Issue March).

Council of Europe (CoE) (2001). Common European Framework of Reference for Languages: Learning, Teaching, Assessment. Cambridge: Cambridge University Press.

Council of Europe (CoE) (2018). The Common European Framework of Reference for Languages: Learning, Teaching, Assessment-Companion Volume with New Descriptors. Strasbourg: CoE.

https://rm.coe.int/cefr-companion-volumewith-new-descriptors-2018/168078798

Darmi, R., Mat Saad, N. S., Abdullah, N., Puteh-Behak, F., Zakaria, Z. A., \& Adnan, J. N. I. A. (2017). Teachers' Views on Students' Performance in English Language Proficiency Courses Via Cefr Descriptors. International E-Journal of Advances in Education, 3, 363-370. https://doi.org/10.18768/ijaedu.336688

Díez-Bedmar, M. B., \& Byram, M. (2019). The Current Influence of the CEFR in Secondary Education: Teachers' Perceptions. Language, Culture and Curriculum, 32, 1-15. https://doi.org/10.1080/07908318.2018.1493492

Don, Z. M. (2015). English Language Proficiency, Graduate Employability and the Role of CEFR. ASEAN Seminar 2015 on "Best Practices in English Teaching in ASEAN Universities". UMrepository.

http://repository.um.edu.my/98438/1/Asean\%20Seminar\%202015\%20English\%20lang uage.pdf

Don, Z. M., Abdullah, M. H., Abdullah, A. C., Lee, B. H., Kaur, K., Pillai, J., \& Hooi, M. Y. (2015). English Language Education Reform in Malaysia: The Roadmap 2015-2025. Putrajaya: Ministry of Education.

Galante, A., Okubo, K., Cole, C., Elkader, N. A., Carozza, N., Wilkinson, C., Wotton, C., \& Vasic, J. (2020). "English-Only Is Not the Way to Go": Teachers' Perceptions of Plurilingual Instruction in an English Program at a Canadian University. TESOL Quarterly, 54, 980-1009. https://doi.org/10.1002/tesq.584

Hufeisen, B., \& Neuner, G. (2004). The Plurilingualism Project: Tertiary Language Learning: German after English. Strasbourg Cedex: Council of Europe.

Lo, Y. Y. (2018). English Teachers' Concern on Common European Framework of Reference for Languages (CEFR): An Application of CBAM. Jurnal Kurikulum \& Pengajaran Asia Pasifik, 6, 13.

Mohamad Uri, N. F., \& Adb Aziz, M. S. (2018). Implementation of CEFR in Malaysia: Teachers' Awareness and the Challenges. 3L: Language, Linguistics, Literature, 24, 168-183. http://ejournal.ukm.my/3l/article/view/24273/8384 https://doi.org/10.17576/3L-2018-2403-13

Ngo, X. M. (2017). Diffusion of the CEFR among Vietnamese Teachers: A Mixed Methods investigation. Asian EFL Journal, 19, 7-32.

Nhung, P. T. H. (2019). Implementing the CEFR at a Vietnamese University-General English Language Teachers' Perceptions. CEFR Journal, 41, 41-67.

Piccardo, E. (2010). From Communicative to Action-Oriented: New Perspectives for a 
New Millennium. Contact Tesl, 36, 20-35.

Piccardo, E. (2013). Plurilingualism and Curriculum Design: Toward a Synergic Vision. TESOL Quarterly, 47, 600-614. https://doi.org/10.1002/tesq.110

Piccardo, E., North, B., \& Goodier, T. (2019). Broadening the Scope of Language Education: Mediation, Plurilingualism, and Collaborative Learning: The CEFR Companion Volume. Journal of E-Learning and Knowledge Society, 15, 17-36.

Read, J. (2019). The influence of the Common European Framework of Reference (CEFR) in the Asia-Pacific Region. LEARN Journal: Language Education and Acquisition Research Network, 12, 12-18.

Ross, A., Hartsmar, N., \& Dooly, M. (2012). Equalities and Education in Europe: Explanations and Excuses for Inequality. Cambridge: Cambridge Scholars Publishing.

Savski, K. (2019). Putting the Plurilingual/Pluricultural Back into CEFR: Reflecting on Policy Reform in Thailand and Malaysia. Journal of Asia TEFL, 16, 644-652. https://doi.org/10.18823/asiatefl.2019.16.2.13.644

Savski, K. (2020). Local Problems and a Global Solution: Examining the Recontextualization of CEFR in Thai and Malaysian Language Policies. Language Policy, 19, 527-547. https://doi.org/10.1007/s10993-019-09539-8

Shahomy, E. (2011). An Engagement with the CEFR. A Critical View and Time. The ALTE 4th International Conference, Krakow, July 2011, 7-9.

Uri, N. F. M., \& Aziz, M. S. A. (2020). The Appropriacy and Applicability of English Assessment against CEFR Global Scale: Teachers' Judgement. 3L: Language, Linguistics, Literature, 26, 53-65. https://doi.org/10.17576/3L-2020-2603-05

Yamat, H., Umar, N. F. M., \& Mahmood, M. I. (2014). Upholding the Malay Language and Strengthening the English Language Policy: An Education Reform. International Education Studies, 7, 197-205. https://doi.org/10.5539/ies.v7n13p197

Yüce, E., \& Mirici, İ. H. (2019). A Qualitative Inquiry into the Application of 9th Grade EFL Program in Terms of the CEFR. Journal of Language and Linguistic Studies, 15, 1171-1187. https://doi.org/10.17263/jlls.631560

Zhao, W., Wang, B., Coniam, D., \& Xie, B. (2017). Calibrating the CEFR against the China Standards of English for College English Vocabulary Education in China. Language Testing in Asia, 7, Article No. 5. https://doi.org/10.1186/s40468-017-0036-1 